\title{
Spectrum Allocation Methods: Studying Allocation through Auctions
}

\author{
Syed Atif Jilani
}

\begin{abstract}
Auctions have been used as a mechanism of selling goods and services for thousands of years.The earliest example of auctions can be traced back to AD 195 when Roman Empire was auctioned off to Julianus. There are numerous examples of Auctions in our daily life but auctions caught the imagination of economists, governments and common people alike when spectrum rights were auctioned by FCC in 1994 in the US. Prior to using auctions for spectrum allocation other methods like administrative process, lottery and first-come-first serve were widely used. Since FCC's auction a number of countries switched to auctions for spectrum allocation because of there comparative advantages over other methods. This paper critically analysis the pros and cons of different methods used in spectrum allocation. The method of using Simultaneous Ascending Auctions in allocation of spectrum is discussed along with the advantages that may accrue from this method.
\end{abstract}

Index Terms-Spectrum allocation methods, simultaneous ascending auctions (SAA).

\section{INTRODUCTION}

From July 1994 to July 1996, the Federal Communications Commission (FCC) conducted nine spectrum auctions, raising about $\$ 20$ billion for the US treasury [1]. These auctions were described as "The Greatest Auction in History" (William Safire, New York Times, March 16, 1995) and "The Auction of the Century" (Liberation, Paris, March 15, 1995) because of their efficiency and sheer volume of revenue they generated [2].

Auctions were first used by the New Zealand government in 1990 to sell spectrum rights. This electromagnetic spectrum is in high demand the world over. By mid 2010, there were nearly 132 countries having access to $3 \mathrm{G}$ technology, India joining late in April 2010 by auctioning off the $3 \mathrm{G}$ spectrum licenses. According to a report in Times of India [3], there are 4.7 billion mobile users worldwide, of which nearly $10 \%$ are $3 \mathrm{G}$ users. For AsiaPacific region only, the projections are pegged at 564 million users by the end of 2013 .

There are different methods like - administrative process, lottery, first-come-first-served and auction-economic theory - by which spectrum rights can be allocated to various firms but auctions works best [4]. Out of these four methods of spectrum allocation, the 1990's has seen a shift of preference from administrative allocation process to auctions. As of now auctions are widely used in United States, Colombia, India, United Kingdom, Argentina, Australia and Hungary.

Manuscript received January 3, 2014; revised March 4, 2014.

Syed Atif Jilani is with the Aligarh Muslim University, Aligarh, India (e-mail: jilani.atif@gmail.com).
This is a conceptual paper based on literature available on spectrum allocation through auctions. In Section II of this paper various methods of spectrum allocation are analysed. Section III covers the review of literature on spectrum allocation by auctions. In Section IV, the design of spectrum auctions is discussed along with the activity rules. Advantages of spectrum allocation through auctions form a part of Section V. Misconceptions regarding auctioning of spectrum rights are examined in Section VI. Finally, Section VII concludes the entire study.

The broader objectives of this study are:

1) To compare the different methods of spectrum allocation employed in different countries;

2) To discuss the activity rules of spectrum auction allocation;

3) To evaluate the advantages of spectrum auctions; and

4) To provide explanation for some of the misconceptions that surround auctions.

\section{Methods of 3G Spectrum Allocation}

Auctions and beauty contests (administrative process) have been the preferred option for the allocation of $3 \mathrm{G}$ spectrum in most of the countries. But in few places in Europe licenses were offered free of charge to the incumbent mobile operators in the Isle of Man, Liechtenstein and Monaco [5]. There are arguments and counterarguments in favour and against of different methods of spectrum allocation.

Auction theorist consider that auctions lead to efficient allocation of spectrum among the bidders while proponents of beauty contest argue that auctions increases the price of spectrum, which has to be ultimately born by the customers. The following Table I provides a comparative analysis of various methods of spectrum allocation in practice:

\begin{tabular}{lllll}
\multicolumn{1}{c}{ S. } \\
No. & Method & $\begin{array}{l}\text { Time } \\
\text { Consumption }\end{array}$ & Efficiency & $\begin{array}{l}\text { Revenue } \\
\text { Generation }\end{array}$ \\
\hline $\mathbf{1}$ & $\begin{array}{l}\text { Administrative } \\
\text { process }\end{array}$ & $\begin{array}{l}\text { Time } \\
\text { consuming }\end{array}$ & $\begin{array}{l}\text { Marked } \\
\text { by red- } \\
\text { tape }\end{array}$ & Not much \\
$\mathbf{2}$ & Lottery & Time efficient & $\begin{array}{l}\text { Least } \\
\text { efficient }\end{array}$ & Not much \\
$\mathbf{3}$ & $\begin{array}{l}\text { First-come- } \\
\text { first-served }\end{array}$ & Time efficient & $\begin{array}{l}\text { Less } \\
\text { efficient }\end{array}$ & Not much \\
& Auction & Time efficient & Efficient & $\begin{array}{l}\text { More } \\
\text { revenue }\end{array}$ \\
& & & &
\end{tabular}

\section{A. Administrative Process}

The earliest method used for spectrum allocation has been 
the administrative process, widely practised in Canada and European Union. This method is also sometimes dubbed as "beauty contest". The criteria for allocation of spectrum is developed by the government and then an in-house committee of experts scan various proposals in light of the government laid criteria. Such a process gives a lot of flexibility to the government in determining the acceptance of a particular proposal. Although, the process is time consuming but the process adheres more to the government plans.

However, this method is not free from critics. It's widely perceived that technical aspects are clearly defined in the criteria set by government but there are subjective criteria like the ability of firm to implement the proposal, the telecom industry concentration and the feasibility of proposal that can't be specified in concrete terms. Some of the criteria are vague and some are not even stated. It provides a lot of room for lobbying and favouritism. This creates a very difficult situation for the applicant firm. They are not aware of the weights assigned to various subjective criteria and not any kind of explanation for rejection of their application. It's the lack of transparency and time consuming nature because of which administrative allocation method is hugely criticised.

\section{B. Lottery}

The second method of spectrum allocation is lottery. It is perceived to be more quick and economical as compared to administrative process. Lotteries too are not free from some serious short comings. They are rejected on the grounds that they lead to speculation and the technical competence of the firm to develop, maintain and operate the license can not be determined through them. After rejecting the administrative process United States experimented with lotteries in allocating cellular licenses during 1980s. Lotteries attracted many speculative applicants, many of whom were not technically competent. Such applicants after winning the licences sold them off to other firms at exorbitant prices leading to notional losses to government coffers.

\section{First-Come-First-Served}

Some of the European Union members resorted to firstcome-first-serve basis of allocation of mobile radio licences. This process has the time advantage but has the same disadvantage as the lottery.

\section{Auction}

In the year 1993, United States decided to switch to auctions for granting new mobile communication licences. The Federal Communication Commission (FCC) was asked to design and operate the auction process for granting licences. The commission came up with a novel method of auction termed as the electronic simultaneous multiple round bidding auction. This method has been copied round the world to sell over US\$100 billion in radio spectrum [6].

Binmore and Klemperer (2002) [7] while advocating for auctions over beauty contests argued that the 'second generation' licenses fetched the UK government only 40,000 pounds as compared to $3 \mathrm{G}$ spectrum auctions which yielded about $2 \frac{1}{2} \%$ of GNP. Spectrum auctions proved that they can play a vital role in nation building by reducing the government debts and lowering the income taxes on public. They extract and provide information to governments which can't be assessed through beauty contests.

\section{LITERATURE REVIEW}

Simultaneous Ascending Auction (SAA) was considered by Klemperer (1999) [8] as the most important new auction design. According to him the germs of SAA can be traced to Vickrey, 1976 but the onus of practically designing such auctions for the first time goes to Milgrom, Wilson and McAfee who proposed the rules that were necessary to make the SAA effective in the context of US radio spectrum auctions.

Cramton (1997) [9] has analysed the six spectrum auctions conducted by FCC from July 1994 to May 1996. Cramton argues that this auction format had theoretical virtues which were never proven. FCC chose to innovate. The auctions went on smoothly with some minor hitches and were termed as very successful. Cramton adds a note of caution also that the success of these auctions doesn't imply that alternative methods were less successful and that the success is assured in future also. Although allocation of spectrum by auctions is a huge improvement over allocation by lottery or comparative hearings.

The British government raised twenty-two billion and half a million pounds in the auction of five telecom licenses. These auctions and a few subsequent European auctions along with FCC auctions can be termed as the greatest auctions after the auction of Roman Empire to Julianus in 195 A.D.

Klemperer (2002) [10] while commenting on Börgers and Dustmann (2002) result's reports that the UK 3G telecom auction of 2000 is considered as the most successful of the Western European 3G auctions in terms of revenue raised per capita and efficiency. The aspect of revenue was most obvious. But the efficiency aspect was probed by different researchers and was found to be efficient or close to be efficient, in the sense of maximizing the sum of the valuations of the license holders. The pre-auction and postauction data suggest that the four-incumbent firms in UK auction were having the highest valuations, so were the efficient winners. Moreover, Vodafone was having the highest incremental value for a large license and so the allocation of spectrum among the winner's was also efficient.

Lueck (1998) [11] describes the opinion of S. Moreton and Pablo T. Spiller deduced from their empirical study of the Personal Communications Service (PCS) auctions of 1995 and 1996 in USA, in which they have shown that the bidder behaviour is consistent with most economists' conceptions of competitive markets. They have also shown that firms competing in these auctions were able to aggregate licenses, thus offering vindication for simultaneous multiple-round auctions.

A detailed description of why auctions were used in spectrum allocations and which format of auction best suited such an allocation is given by Börgers and Damme (2003) [12]. They have argued that a seller wants to get the best price for the item which he/she is selling. This 
objective gets slightly modified if the seller happens to the government instead of a private-sector seller. Compared to revenue generation, the government will be more interested in achieving an efficient outcome - placing the license into the hands of those who value them the most. Although more revenues are also desired as they help the government to reduce the fiscal deficits and taxes. An ascending auction provides an attractive alternative, which itself can be modified to suit the particular need.

By empirically analysing the data from the 1995 US Broadband PCS auctions Klemperer and Pagnozzi (2002) [13] have concluded that when the number of objects available exactly equals the number of "advantaged" bidders, revenues will be lower in an ascending auction. A fall in revenues is because of the reluctance of the weaker bidders to participate in the auction, and those that are present bid extremely cautiously because of the enhanced 'winner's curse' they face. In US, revenues were lower when there were exactly two "advantaged" bidders among the bidders for the two licences in an area, than when there were either few or more than two advantaged bidders. They have estimated a revenue loss of around $15 \%$ to the government in such cases.

Hafalir and Krishna (2006) [14] have pondered over the idea of restriction on the resale of spectrum once sold in the secondary market. They believe that with asymmetric bidders, the resulting inefficiencies create a motive for postauction trade. Even a ban on such a resale can be easily circumvented, as happened in $3 \mathrm{G}$ spectrum licences of UK. The government banned the resale of license and TIW, a Canadian company, bid successfully for the most valuable license "A". However, Hutchison, a rival company, then acquired the license by buying TIW itself.

\section{Spectrum Auction Design}

The method being proposed by theorist to FCC for spectrum allocation is known as Simultaneous Ascending Auction (SAA). Under the method used - all licenses were open for bidding simultaneously and remained open until bidding on all ceases. This means that instead of selling licenses, one by one, they were open for bidding at the same time and all the licenses would remain open until bidding ceased on all of them. Bidding occurred in rounds and bids were announced after each round. This helped in containing the winner's curse and thus boosted the confidence of bidders. They started bidding more aggressively.

Since the licenses are interdependent - there aggregate value may exceed the sum of their individual values - by simultaneous bidding, bidders were able to build efficient license aggregations. The FCC auctions are considered as the best example where synergies play a critical role [15]. Synergies often arise from owning licences in adjacent geographical locations or adjacent frequencies.

Bidders were having an initial eligibility based on their deposits and were supposed to remain active to maintain their eligibility. Activity was defined as the sum of standing high bids and new bids.

$$
\text { Activity }=\text { Standing high bids }+ \text { New bids }
$$

Insufficient activity reduces the eligibility to win. The auction proceeded in three stages:

- Stage 1: bid at least $50 \%$ of eligibility

- Stage 2: bid at least $80 \%$ of eligibility

- Stage 3: bid at least $100 \%$ of eligibility

Bidders were not supposed to bid more than their eligibility. If the activity of a bidder reduces than his/her eligibility to win the auction also get reduced. A withdrawal penalty was also imposed. If a winner wants to withdraw then he/she was to surrender the license. The process of auction will start again and the withdrawer would have to pay the difference between current highest bid and his final price in case the present bid is lower than the previous final price.

\section{Advantages of Spectrum Auctions}

Auctions are considered to be more efficient in allocating the licence to that firm which can best make use of them. This is so because the firm which has the ability to start the services quickly, which can introduce new services and which believes it can utilize the spectrum more efficiently will value the spectrum more. This valuation will lead to higher bidding and more revenue generation for the government. Thus the auction designs which award the licences to those bidders who have the highest willingness to pay promote the efficient use of spectrum.

The advantages of auctions over other methods of spectrum allocation are:

1) Auctions help in revealing the value of a license as perceived by the bidders;

2) Auctions are quicker and more efficient as compared with administrative procedures;

3) Auctions are more transparent;

4) Auctions are flexible, i.e. can be moulded in such a fashion so as to suit the government policies.

The last point of flexibility needs further qualification. Suppose that the government desires to allocate a certain portion of spectrum to women or say economically weaker section of society. Based on this policy government insert a clause in the auction rules that, say for example, $10 \%$ of the spectrum will be allocated to reserved categories or the bids from such and such categories will be calculated by adding $10 \%$ to their bid value. Such reserved category firms can even be asked to pay in instalments.

Auction rules can be twisted to achieve other broader policy objectives of the government. Innovators can be rewarded by giving preference to them by making provisions in auction rules. In case the government feels that mobile or telecommunication facility needs to be provided to rural areas or far off places, special rewards can be given to firms willing to offer services in those areas. Monopolies can also be checked by framing rules in such a fashion that limits the spectrum with a particular firm. Thus auctions are capable of including most of the criteria of administrative procedure if they can be expressed in precise and explicit terms.

\section{MISCONCEPTIONS}

There are two flawed arguments which are given against 
the auctions. First one is that the auctions take away the discretionary powers from the government. Second is that ownership of spectrum is sold to the bidders and hence it's difficult to reallocate it in future. On the face of it both the arguments are wrong.

First of all the government can control the auctions by including the desired policy decisions when the rules for auction methods are being framed. The auctions merely require the government to state all the policy decisions beforehand. Such a condition avoids unnecessary bureaucratic interventions and is very important for developing the morale of the investors. Secondly, ownership of spectrum doesn't get transferred with auctioning of it. There is only the transfer of spectrum rights and not the spectrum itself in the auction.

It's also argued that spectrum not be auctioned but should be given away because auctioning will increase the cost which the customers will have to pay ultimately. Moreover, spectrum being a natural resource should not be auctioned but should be made available free of cost to the firm which can is able to provide better services. Both of these philanthropic ideas seem to be far-off from reality.

In practise the cost of auction is born by the firm in the beginning and constitutes its fixed cost. So as per the concept of marginal cost there will be no additional burden on the customers as marginal cost doesn't includes the fixed cost. Auctions just transfer the firms profit into the government coffers.

As spectrum is a scare resource - it can't be given free of cost. Spectrum has a price tag attached to it - whether implicit or explicit. It has often been noticed that the valuations of a firm depend to a considerable extent on the number of licenses with that firm. Moreover, if spectrum being a natural resource be given free of cost why not other such resources like petroleum and natural gas. Hence such arguments are very much against the market practices and can be rejected easily.

\section{CONCLUSIONS}

Methods of allocation of public assets have been debated highly amongst corporate, government and academic circles. Governments all over the world have found themselves in tricky conditions as far as allocation of spectrum rights; coal blocks; oil leases and other assets are concerned. Traditionally these allocations were mainly accomplished through administrative process where governments decided whom to allocate assets and how much as per their own laid down criteria. This method is criticized for being time consuming along with being more bureaucratic in nature. Other methods like lottery systems and first-come-firstserve also have their limitations of being low on efficient allocation and less profitable for the government. Auctions were first used for allocating spectrum rights in the US in 1993. This allocation was considered to be more efficient in terms of revenue generated for the government as compared to other forms of allocations. The auction design used was simultaneous ascending auction where all licences were open for bidding simultaneously until bidding on all ceases.

Some researchers [10] are of the opinion that though auctions have resulted in successful outcomes but they cannot be applied in all cases. Caution must be taken while deciding on the choice of alternative for allocation of public assets. Failure of spectrum allocation in some countries has also corroborated the stand of these researchers. The success of the auction depends on the mechanism design. One size fit all approach would not be a good option for allocation of public assets.

\section{REFERENCES}

[1] P. Cramton, "The efficiency of the FCC spectrum auctions," Journal of Law and Economics, vol. 75, pp. 727-736, 1998.

[2] R. P. McAfee. (1995). Auction Design for the Real World. The University of Texas. [Online]. Available: http://www.mcafee.cc/Papers/Bin/Auction.pdf

[3] S. Singh, "India among last nations to get in," The Times of India, April 12, 2010.

[4] J. McMillan, "Why auction the spectrum?" Graduate School of International Relations and Pacific Studies, University of California, San Diego, 1994.

[5] (July/August 2003). International Telecom Union. Third-Generation (3G) Mobile - A Status Report. ITU News. [Online]. 6 Available: http://www.itu.int/itunews/issue/2003/06/thirdgeneration.html

[6] R. P. McAfee, J. McMillan, and S. Wilkie, "The greatest auction in history," in Better Living Through Economics, ed., John Siegfried, Harvard University Press, 2010, pp.168-184.

[7] K. Binmore and P. Klemperer, "The biggest auction ever: The sale of the British 3G telecom licenses," The Economics Journal, vol. 112, pp. 74-96, March, 2002.

[8] P. Klemperer, "Auction theory: A guide to literature," Journal of Economic Surveys, vol. 13, no. 3, pp. 227-286, 1999.

[9] P. C. Cramton, "The FCC spectrum auctions: An early assessment," Journal of Economics and Management Strategy, vol. 6, no. 3, pp. 431-495, 1997.

[10] P. Klemperer. (1992). Some observations on the British and German 3G telecom auctions. [Online]. Available: http://www.nuff.ox.ac.uk/users/klemperer/totalpdfbritish7german.pdf

[11] D. Lueck, "Auctions, markets, and spectrum ownership: comment on moreton and spiller," Journal of Law and Economics, vol. 41, no. 2 , pp. 717-725, 1998.

[12] T. Börgers and E. Damme, "Auction theory for auction design," TILEC Discussion Paper, Tilburg University, 2003.

[13] P. Klemperer and M. Pagnozzi. (2002). Advantaged bidders and spectrum prices: an empirical analysis. [Online]. Available: http://www.paulklemperer.org

[14] I. Hafalir and V. Krishna, "Asymmetric auctions with resale," American Economic Review, vol. 98, no. 1, pp. 87-112, 2006.

[15] E. Katok and A. E. Roth, "Auctions of homogenous goods with increasing returns: experimental comparison of alternative 'Dutch' auctions," Management Science, vol. 50, no. 8, pp. 1044-1063, 2004.

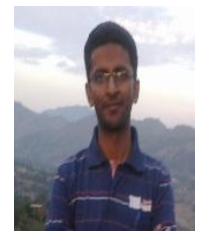

Syed Atif Jilani was born at Rampur, India on May 1, 1984. Presently, he is pursuing research in Islamic finance from Aligarh Muslim University as senior research Fellow (SRF). He did his MBA (finance) from Department of Business Administration, AMU, Aligarh in 2007 and graduation in Physics (hons.) in 2005 from the same university. $\mathrm{He}$ is having a rich industry experience in finance and accounting, having served at Indiabulls Securities Limited, Gurgaon as a senior executive in the accounts and finance department. His areas of interest include auctions, game theory, stock markets, derivatives, and Islamic finance. 